\title{
Race, Mineral Homeostasis and Mortality in Patients with End-Stage Renal Disease on Dialysis
}

\author{
Julia J. Scialla ${ }^{a, b}$ Rulan S. Parekh ${ }^{c}$ Joseph A. Eustace ${ }^{d}$ Brad C. Astor $^{e}$ \\ Laura Plantinga $^{f}$ Bernard G. Jaarg, ${ }^{g}$ Tariq Shafig Josef Coresh ${ }^{g, i, j}$ \\ Neil R. Powe ${ }^{k}$ Michal L. Melamed' \\ a University of Miami Miller School of Medicine, Miami, Fla., and ${ }^{b}$ Department of Medicine and Duke Clinical \\ Research Institute, Duke University School of Medicine, Durham, N.C., USA; ${ }^{\circ}$ Hospital for Sick Children, University \\ Health Network and University of Toronto, Toronto, Ont., Canada; ${ }^{d}$ HRB Clinical Research Facility, University

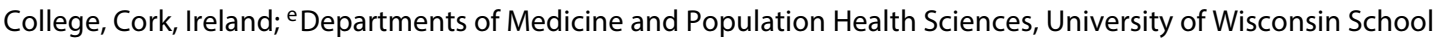 \\ of Medicine and Public Health, Madison, Wis., f Department of Epidemiology and Laney Graduate School, Emory \\ University, Atlanta, Ga., ${ }^{9}$ Department of Medicine, Johns Hopkins University School of Medicine, ${ }^{\mathrm{h}}$ Nephrology \\ Center of Maryland, and Departments of 'Epidemiology and 'Biostatistics, The Johns Hopkins Bloomberg School \\ of Public Health, Baltimore, Md., ${ }^{k}$ San Francisco General Hospital and University of California San Francisco, \\ San Francisco, Calif., and 'Departments of Medicine and Epidemiology and Population Health, Albert Einstein \\ College of Medicine, Bronx, N.Y., USA
}

\section{Key Words}

Dialysis · End-stage renal disease · Epidemiology ·

Fibroblast growth factor $23 \cdot$ Phosphorus · Vitamin D

\begin{abstract}
Background: Abnormalities in mineral homeostasis are ubiquitous in patients on dialysis, and influenced by race. In this study, we determine the race-specific relationship between mineral parameters and mortality in patients initiating hemodialysis. Methods: We measured the levels of fibroblast growth factor 23 (FGF23) and 25-hydroxyvitamin D (25 D) in 184 African American and 327 non-African American hemodialysis patients who enrolled between 1995 and 1998 in the Choices for Healthy Outcomes in Caring for ESRD Study. Serum calcium, phosphorus, parathyroid hormone (PTH) and total alkaline phosphatase levels were
\end{abstract}

averaged from clinical measurements during the first 4.5 months of dialysis. We evaluated the associated prospective risk of mortality using multivariable Cox proportional hazards models stratified by race. Results: PTH and total alkaline phosphatase levels were higher, whereas calcium, phosphorus, FGF23 and 25 D levels were lower in African Americans compared to those of non-African Americans. Higher serum phosphorus and FGF23 levels were associated with greater mortality risk overall; however, phosphorus was only associated with risk among African Americans (HR 5.38, 95\% Cl 2.14-13.55 for quartile 4 vs. 1), but not among non-African Americans ( $p$-interaction $=0.04$ ). FGF23 was associated with mortality in both groups, but more strongly in African Americans (HR 3.91, 95\% Cl 1.74-8.82 for quartiles 4 vs. 1; p-interaction $=0.09$ ). Serum calcium, PTH, and $25 \mathrm{D}$ levels were not consistently associated with mortality. The lowest and highest quartiles of total alkaline phosphatase were as-

\section{KARGER 125}

(C) 2015 S. Karger AG, Base

$0250-8095 / 15 / 0421-0025 \$ 39.50 / 0$ 
sociated with higher mortality risk, but this did not differ by race $(p$-interaction $=0.97)$. Conclusions: Aberrant phosphorus homeostasis, reflected by higher phosphorus and FGF23, may be a risk factor for mortality in patients initiating hemodialysis, particularly among African Americans.

(c) 2015 S. Karger AG, Basel

\section{Introduction}

Abnormalities of mineral homeostasis are among the most potent risk factors for adverse outcomes in the ESRD population and are potentially modifiable $[1,2]$. Elevation in serum phosphorus levels due to inadequate renal and dialytic clearance, contributes to rising levels of phosphorus regulatory hormones, parathyroid hormone (PTH) and fibroblast growth factor 23 (FGF23). Elevated levels of FGF23 inhibit the production of 1-a hydroxylase, which converts 25 -hydroxyvitamin $\mathrm{D}(25 \mathrm{D})$ to active 1,25-dihydroxyvitamin $\mathrm{D}$. This induces 1,25-dihydroxyvitamin D deficiency, thereby contributing to further elevation of $\mathrm{PTH}$, impaired calcium absorption and abnormal bone turnover [3]. The resulting abnormalities in mineral and bone homeostasis may contribute to the pathogenesis of cardiovascular disease in patients with ESRD by promoting vascular calcification [4], left ventricular hypertrophy and fibrosis $[5,6]$, and sudden cardiac death $[7,8]$.

Levels of these mineral and bone parameters differ between African Americans and non-African Americans [9], with higher PTH and phosphorus levels and lower FGF23 and 25 D levels commonly observed in African Americans on dialysis $[1,10]$. The consequences of abnormalities in mineral homeostasis may also differ by race as highlighted by a recent study among a racially diverse population of young adults in which deficiency of $25 \mathrm{D}$ was associated with coronary heart disease in Caucasians, but not in African Americans [11]. Findings such as these suggest that race-specific targets for mineral and bone parameters may be needed.

Our group previously reported that elevated levels of serum calcium, phosphorus and PTH were each associated with an increased risk of mortality in incident dialysis patients enrolled in the Choices for Healthy Outcomes in Caring for End-Stage Renal Disease (CHOICE) Study [12]. In this study, we extend these findings to include measurements of FGF23, total alkaline phosphatase and $25 \mathrm{D}$ and test the hypothesis that the association of mineral homeostasis with mortality differs by race.

\section{Subjects and Methods}

\section{Study Population}

All participants included in this study were recruited as part of the CHOICE Study between 1995 and 1998 from dialysis clinics affiliated with Dialysis Clinic, Inc. (DCI, Nashville, Tenn., USA). Inclusion criteria for CHOICE included the initiation of chronic outpatient dialysis within the past 6 months, ability to provide informed consent for participation, age older than 17 years, and ability to speak English or Spanish. Samples were drawn from hemodialysis patients prior to dialysis treatments, immediately processed and stored at $-80^{\circ} \mathrm{C}$. This analysis includes the 184 African American and 327 non-African American participants with samples available in the specimen bank. Although the initial CHOICE cohort included both peritoneal and hemodialysis patients, only those on hemodialysis contributed to the specimen bank. The Johns Hopkins University School of Medicine Institutional Review Board and the review boards for each clinical center approved the study protocol and all patients gave their written informed consent.

\section{Exposure}

The primary exposures for this study were serum calcium, phosphorus, $\mathrm{PTH}$, and total alkaline phosphatase, and plasma FGF23 and 25 D. Serum calcium, phosphorus, PTH and total alkaline phosphatase levels were calculated as the average of all clinical measurements performed during routine dialysis care up to 4.5 months after enrollment to correspond to the time when FGF23 and $25 \mathrm{D}$ levels were measured. A majority of participants had 5 measurements of calcium (95\%), phosphorus $(95 \%)$ and total alkaline phosphatase (85\%), and 1-2 measurements of PTH (77\%; $10.4 \%$ had $>2$ measurements of PTH) in the time interval. PTH was measured using the Diasorin intact assay (Diasorin, Inc., Stillwater, Minn., USA). Serum calcium levels were not corrected for albumin in primary analyses due to the adjustment for serum albumin in multivariable models, and because the use of albuminadjusted calcium did not qualitatively change the findings (data not shown). C-terminal FGF23 (Immutopics, San Clemente, Calif., USA) and 25 D (Immunodiagnostic Systems, Scottsdale, Ariz., USA) were measured at a single timepoint in stored plasma samples drawn within 6 months of enrollment (median of 90 days).

\section{Covariates}

Demographics and medical history were ascertained by a combination of self-report and chart review. Race was classified as either African American $(\mathrm{n}=184 ; 36 \%)$ or non-African American $(\mathrm{n}=327 ; 64 \%)$, which included Caucasian $(\mathrm{n}=295)$ and other races $(n=32)$. Baseline atherosclerotic cardiovascular disease was defined as a history of coronary artery disease, myocardial infarction, cerebrovascular disease, peripheral vascular disease or transient ischemic attack prior to dialysis initiation. The presence and severity of comorbidity were assessed using the Index of Coexistent Disease (ICED), an instrument that has been validated in dialysis populations $[13,14]$. Body mass index (BMI) was calculated based on the height and weight reported on Centers for Medicare \& Medicaid Services Form 2728 that is completed by providers at dialysis initiation. Laboratory covariates include serum albumin and hemoglobin measured as the average of all clinical measurements up to 4.5 months after enrollment. High-sensitivity C-reactive protein (CRP) and interleukin-6 (IL-6) were measured as previously reported [15].
26

Am J Nephrol 2015;42:25-34

DOI: $10.1159 / 000438999$
Scialla/Parekh/Eustace/Astor/Plantinga/ Jaar/Shafi/Coresh/Powe/Melamed 


\section{Outcomes}

The primary outcome is all-cause mortality ascertained through December 31, 2008 using direct contact with dialysis clinics and through data linkage to the United States Renal Data System, the national registry of patients with ESRD in the United States. Date of death is directly ascertained in the United States Renal Data System through mandated reporting. The secondary outcome is atherosclerotic cardiovascular death, defined as a death with an immediate or underlying cause attributed to coronary artery disease, cerebrovascular disease, peripheral vascular disease, and abdominal aortic aneurysm or ischemia. Causes of death were ascertained through the National Death Index and adjudication by trained physicians, as previously described [15], and were available through December 31, 2004. Both outcomes were censored at the time of kidney transplantation and secondary analyses were censored for death due to non-cardiovascular causes.

\section{Statistical Analysis}

Descriptive statistics were used to compare the characteristics of CHOICE participants that were included in our study population versus not, and characteristics by African American versus non-African American race. Levels of mineral parameters were classified in quartiles. FGF23 and PTH were log transformed for continuous analyses.

We evaluated the cumulative incidence of death by levels of each mineral parameter and race using the Kaplan-Meier method and the log rank test. Due to measurement of the exposure in stored specimens collected after dialysis initiation, participants were left censored to the time of measurement. We modeled the hazard of death using Cox proportional hazards models adjusted for age, sex, race, education (less than high school, high school graduate, college graduate or declined to answer), smoking, BMI, ICED, diabetes mellitus, history of atherosclerotic cardiovascular disease, serum albumin and hemoglobin, accounting for correlation within dialysis clinic clusters using stratification. Missing data were handled by model-wise deletion. Nine percent of participants were missing a covariate and therefore were not included in fully adjusted models. These participants did not differ from those included in fully adjusted models in terms of age, sex, comorbidity index or history of diabetes mellitus or cardiovascular disease (data not shown), but were more likely to be African American $(\mathrm{p}=0.02)$.

We stratified models by race and tested interactions by race in models including mineral parameters as continuous variables. In these interaction models, PTH and total alkaline phosphatase were modeled using restricted cubic splines with knots at the 10th, 50th and 90th percentiles due to evidence of a nonlinear association with mortality in this and other studies [16]. In secondary analyses, we conducted similar analyses with risk of cardiovascular mortality.

In sensitivity analyses, we additionally adjusted primary models for the inflammatory markers, CRP and IL-6, and repeated analyses using race-specific quartiles of each mineral parameter. We accounted for the impact of missed dialysis treatments, as a measure of poor adherence to treatment, on both mineral parameters and outcomes with analyses restricted to the subset of the population who missed $\leq 3 \%$ of scheduled dialysis treatments over a median of 3.6 years (interquartile range (IQR) 2.1-4.9 years). Finally, we accounted for differing levels of residual renal function by performing analyses restricted to participants who reported $\geq 250 \mathrm{ml}$ of urine per day at study enrollment $(\mathrm{n}=392)$. Statistical analyses were performed using Stata (Special Edition, version 11.1; Stata Corporation, College Station, Tex., USA). Two-sided p values $\leq 0.05$ were considered significant, except for tests of interaction for which $\mathrm{p} \leq 0.10$ was considered significant due to reduced power in these comparisons.

\section{Results}

The study population includes 511 participants on hemodialysis from CHOICE with samples available for measurement of FGF23 and 25 D. Participants had lower educational attainment, higher serum albumin, calcium and phosphorus, lower hemoglobin, and were more likely to have diabetes and higher ICED compared to those without samples available $(\mathrm{n}=530$; online suppl. table 1 ; for all online suppl. material, see www.karger.com/doi/ 10.1159/000438999). Participants enrolled in CHOICE a median of 51 days after dialysis initiation (IQR 31-79) and began to accrue follow-up in this study a median of 145 days (IQR 113-184) after dialysis initiation, at the time blood samples were obtained. The mean age was $58 \pm 15$ years. Fifty seven percent of the study population had diabetes and 56\% had atherosclerotic cardiovascular disease. Among those with medication information available, only $12 \%$ were using intravenous calcitriol at enrollment and this did not differ by race $(\mathrm{p}=0.39)$. African American participants were younger, less likely to have cardiovascular disease and had lower ICED compared to non-African Americans, among other differences (table 1).

Baseline serum calcium level in the study population was $9.3 \pm 0.6 \mathrm{mg} / \mathrm{dl}$, with $6 \%$ of participants above 10.2 and $7 \%$ below $8.5 \mathrm{mg} / \mathrm{dl}$. Baseline serum phosphorus level was $5.4 \pm 1.3 \mathrm{mg} / \mathrm{dl}$ and $44 \%$ of the population was $>5.5$ $\mathrm{mg} / \mathrm{dl}$. Median FGF23 was 1,577 RU/ml (IQR 818-4,946), median PTH was $148 \mathrm{pg} / \mathrm{ml}$ (IQR 70-286), median $25 \mathrm{D}$ was $13.0 \mathrm{ng} / \mathrm{ml}$ (IQR 9.7-17.2) and median total alkaline phosphatase was 89 IU/l (IQR 68.8-113.5). African Americans had higher levels of PTH and total alkaline phosphatase, but lower levels of calcium, phosphorus, FGF23 and $25 \mathrm{D}$ than non-African Americans (online suppl. fig. 1).

Over a median of 3.4 years of follow-up (IQR 1.8-5.9), 361 participants died from any cause (incidence rate 196 per 1,000 person-years). Cause-specific mortality was ascertained over a shorter interval (median 3.4 years), during which 159 participants died from cardiovascular causes (incidence rate 88 per 1,000 person-years). Cumu- 
Table 1. Baseline characteristics of study population by race

\begin{tabular}{|c|c|c|c|c|}
\hline \multicolumn{5}{|l|}{ Sociodemographics } \\
\hline Age, years & $57.9 \pm 14.8$ & $54.6 \pm 14.2$ & $59.8 \pm 14.8$ & $<0.001$ \\
\hline Female sex & $231(45)$ & $96(52)$ & $135(41)$ & 0.02 \\
\hline High school graduate & $331(65)$ & $98(53)$ & $233(71)$ & $<0.001$ \\
\hline \multicolumn{5}{|l|}{ Clinical } \\
\hline Ever smoked & $294(58)$ & $106(58)$ & $188(57)$ & 0.99 \\
\hline $\mathrm{BMI}, \mathrm{kg} / \mathrm{m}^{2}$ & $27.4 \pm 7.3$ & $28.0 \pm 7.7$ & $27.1 \pm 7.1$ & 0.18 \\
\hline Diabetes mellitus & $292(57)$ & $110(60)$ & $182(56)$ & 0.39 \\
\hline Atherosclerotic cardiovascular disease & $284(56)$ & $86(47)$ & $198(61)$ & 0.002 \\
\hline Index of coexistent disease & & & & 0.03 \\
\hline $0-1($ low $)$ & $150(29)$ & $66(36)$ & $84(26)$ & \\
\hline$\geq 250 \mathrm{ml} /$ day & $392(76.7)$ & $131(71.2)$ & $261(79.8)$ & \\
\hline \multicolumn{5}{|l|}{ Laboratory } \\
\hline Albumin, g/dl & $3.72 \pm 0.31$ & $3.70 \pm 0.30$ & $3.72 \pm 0.32$ & 0.51 \\
\hline Hemoglobin, g/dl & $10.9 \pm 1.0$ & $10.6 \pm 1.1$ & $11.0 \pm 0.9$ & $<0.001$ \\
\hline Calcium, mg/dl & $9.3 \pm 0.6$ & $9.1 \pm 0.5$ & $9.3 \pm 0.6$ & $<0.001$ \\
\hline Phosphorus, mg/dl & $5.4 \pm 1.3$ & $5.2 \pm 1.2$ & $5.6 \pm 1.3$ & $<0.001$ \\
\hline Intact parathyroid hormone, $\mathrm{pg} / \mathrm{ml}$ & $148(70-286)$ & $206(108-361)$ & $115(61-252)$ & $<0.001$ \\
\hline FGF23, RU/ml & $1,577(818-4,946)$ & $1,280(603-3,546)$ & $2,133(1,004-6,089)$ & $<0.001$ \\
\hline $25 \mathrm{D}, \mathrm{ng} / \mathrm{ml}$ & $13.0(9.7-17.2)$ & $11.9(9.2-14.6)$ & $13.9(10.0-18.8)$ & $<0.001$ \\
\hline Total alkaline phosphatase, IU/l & $89.0(68.8-113.5)$ & $92.3(70.2-125.5)$ & $87.1(67.5-107)$ & 0.03 \\
\hline $\mathrm{CRP}, \mathrm{mg} / \mathrm{l}$ & $4.3(1.7-11.1)$ & $3.9(1.4-9.8)$ & $4.4(2.2-12.4)$ & 0.04 \\
\hline
\end{tabular}

Data are presented as mean $\pm \mathrm{SD}, \mathrm{n}(\%)$ or median $(\mathrm{IQR}) .{ }^{\ddagger} \mathrm{p}$ values for comparison between races by chi-square, one-way ANOVA or the Kruskal-Wallis test.

lative survival was higher among African Americans compared to non-African Americans $(\mathrm{p}<0.001)$. Cumulative survival according to each mineral parameter and race is depicted in figure 1.

\section{Association of Serum Calcium with Mortality}

Higher serum calcium levels were not associated with the risk of mortality after demographic adjustment ( $\mathrm{p}=$ 0.10 ). The risk of mortality was higher in the second quartile of serum calcium (8.9-9.2 $\mathrm{mg} / \mathrm{dl}$ ) after full adjustment (HR 2.10, 95\% CI 1.45-3.05), but not in demographic adjusted models $(\mathrm{p}=0.16)$, and there was no linear relationship in continuous analyses $(p=0.72)$. When stratified by race, this overall pattern was observed among nonAfrican Americans, but not African Americans, although the interaction was not statistically significant (table 2; $\mathrm{p}=0.20)$.
Association of Serum Phosphorus with Mortality

Similar to prior studies [17], higher quartiles of serum phosphorus were not associated with higher mortality in univariate analyses, but a significant association emerged after demographic adjustment (HR 1.46, 95\% CI 1.012.09 for highest compared with lowest; HR 1.14 per $1 \mathrm{mg} /$ dl higher phosphate in continuous analyses, 95\% CI 1.031.26) and persisted with full adjustment (table 2). The associations were stronger among African Americans (p-interaction $=0.04)$ with an over 5-fold higher risk among African Americans in the highest quartile compared to the lowest (HR 5.38, 95\% CI 2.14-13.55; table 2).

\section{Association of FGF23 with Mortality}

Higher FGF23 was associated with greater mortality in continuous models that were demographic-adjusted $(\mathrm{p}=0.01)$ and fully adjusted (table $2 ; \mathrm{p}=0.004)$. A graded 


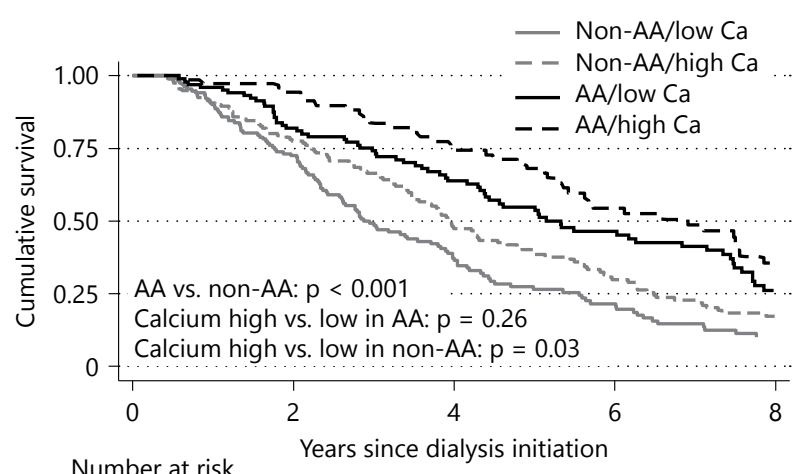

Number at risk

$\begin{array}{llllllll}\text { Non-AA/low Ca } & 99 & 65 & 44 & 27 & 22 & 13 & 8\end{array}$ $\begin{array}{llllllll}\text { AA/low Ca } & 86 & 75 & 59 & 46 & 38 & 30 & 15\end{array}$ $\begin{array}{llllllll}\text { Non-AA/high Ca } & 117 & 94 & 61 & 46 & 34 & 26 & 14\end{array}$ $\begin{array}{lllllllll}\text { a } & \mathrm{AA} / \text { high Ca } & 64 & 54 & 49 & 43 & 30 & 24 & 14\end{array}$

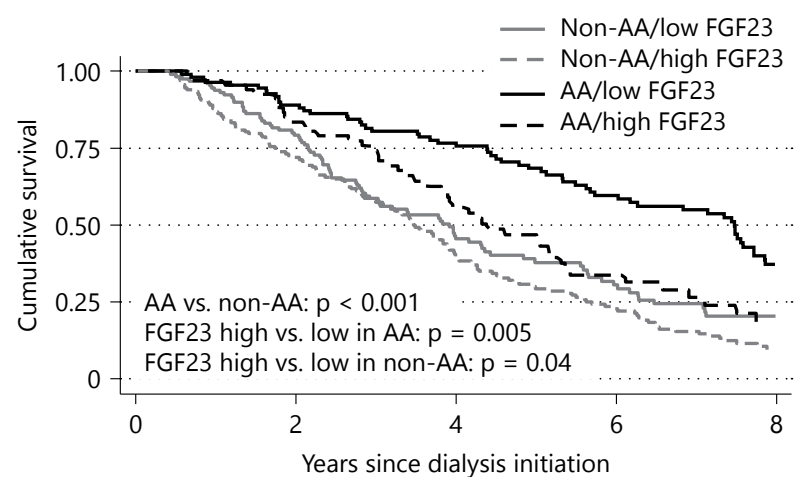

Number at risk

$\begin{array}{llllllll}\text { Non-AA/low FGF23 } & 100 & 68 & 47 & 32 & 25 & 18 & 13\end{array}$

$\begin{array}{llllllll}\text { AA/low FGF23 } & 96 & 84 & 77 & 65 & 53 & 45 & 23\end{array}$

$\begin{array}{llllllll}\text { Non-AA/high FGF23 } & 116 & 91 & 58 & 41 & 31 & 21 & 9\end{array}$

$\begin{array}{lllllllll}\text { C } & \text { AA/high FGF23 } & 55 & 46 & 32 & 25 & 16 & 10 & 7\end{array}$

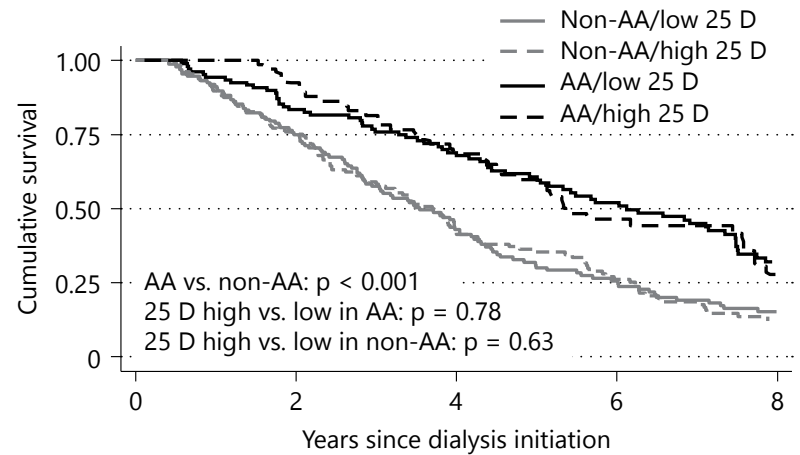

Number at risk

$\begin{array}{llllllll}\text { Non-AA/low 25 D } & 100 & 75 & 53 & 34 & 28 & 20 & 14\end{array}$

$\begin{array}{llllllll}\text { AA/low } 25 \mathrm{D} & 91 & 79 & 68 & 58 & 45 & 38 & 21\end{array}$

$\begin{array}{llllllll}\text { Non-AA/high 25 D } & 116 & 84 & 52 & 39 & 28 & 19 & 8\end{array}$

e $\quad$ AA/high 25 D $60 \begin{array}{lllllll}60 & 51 & 41 & 32 & 24 & 17 & 9\end{array}$

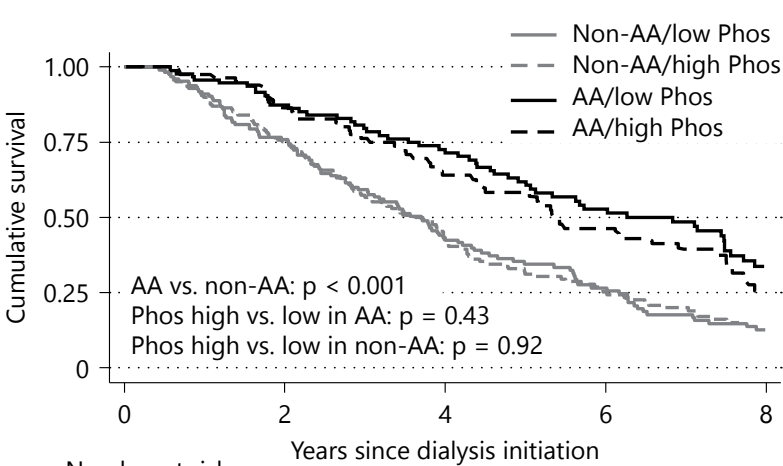

Number at risk

$\begin{array}{llllllll}\text { Non-AA/low Phos } & 103 & 76 & 53 & 36 & 27 & 18 & 11\end{array}$

$\begin{array}{llllllll}\text { AA/low Phos } & 81 & 70 & 62 & 50 & 39 & 32 & 19\end{array}$

$\begin{array}{llllllll}\text { Non-AA/high Phos } & 113 & 83 & 52 & 37 & 29 & 21 & 11\end{array}$

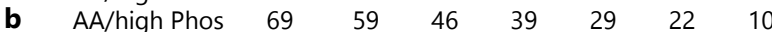

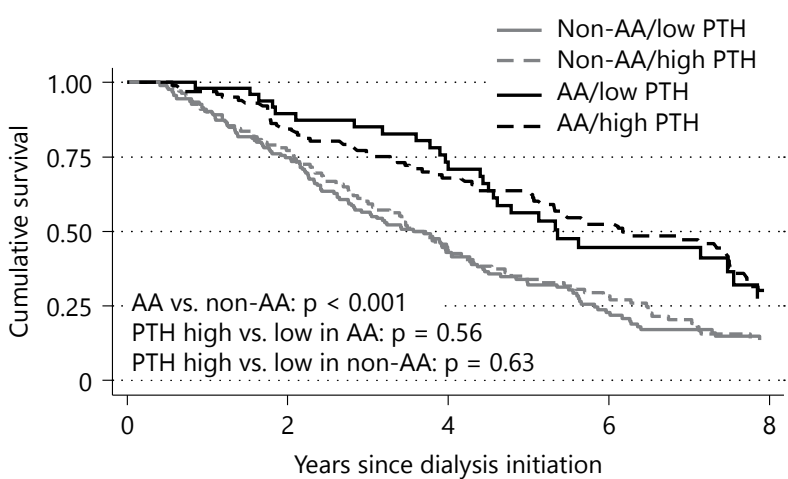

Number at risk

$\begin{array}{llllllll}\text { Non-AA/low PTH } & 115 & 80 & 56 & 36 & 24 & 17 & 10\end{array}$

$\begin{array}{llllllll}\text { AA/low PTH } & 42 & 37 & 31 & 22 & 15 & 13 & 6\end{array}$

$\begin{array}{llllllll}\text { Non-AA/high PTH } & 82 & 63 & 41 & 30 & 25 & 17 & 10\end{array}$

$\begin{array}{llllllll}\text { d } \quad \text { AA/high PTH } & 85 & 75 & 63 & 57 & 44 & 35 & 19\end{array}$

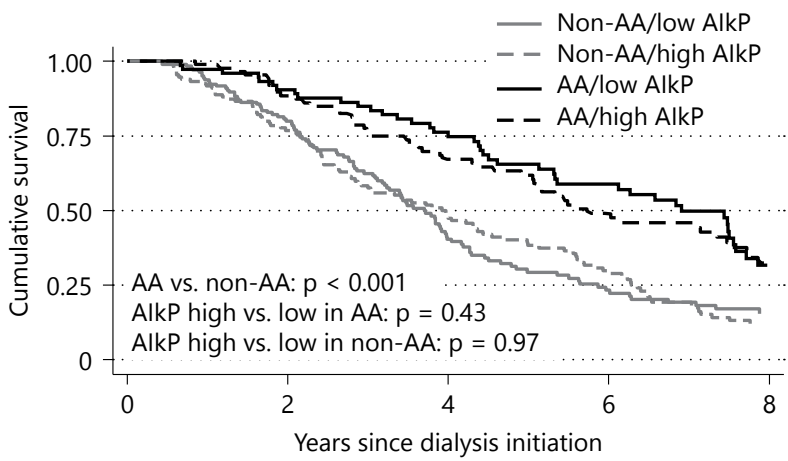

$\begin{array}{rccccccc}\text { Number at risk } & & & & & & \\ \text { Non-AA/low AlkP } & 111 & 80 & 47 & 30 & 23 & 18 & 9 \\ \text { AA/low AlkP } & 65 & 60 & 51 & 42 & 35 & 25 & 11 \\ \text { Non-AA/high AlkP } & 100 & 74 & 55 & 41 & 31 & 19 & 12 \\ \text { f AA/high AlkP } & 75 & 61 & 52 & 44 & 32 & 29 & 18\end{array}$

(low FGF) vs. $\geq 1,590$ (high FGF); PTH $<150$ (low PTH) vs. $\geq 150$; $25 \mathrm{D}<13.0$ (low $25 \mathrm{D}$ ) vs. $\geq 13.0$ (high $25 \mathrm{D}$ ); and total alkaline phosphatase $\leq 89.0$ (low AlkP) vs. $>89.0$ (high AlkP). p values are derived using the log-rank test. a Serum calcium. b Serum phosphorus. c FGF23. d PTH. e 25 D. f Total alkaline phosphatase. 
Table 2. Adjusted ${ }^{\dagger}$ hazard ratio $(95 \% \mathrm{CI})$ of mortality by mineral parameters and stratified by race

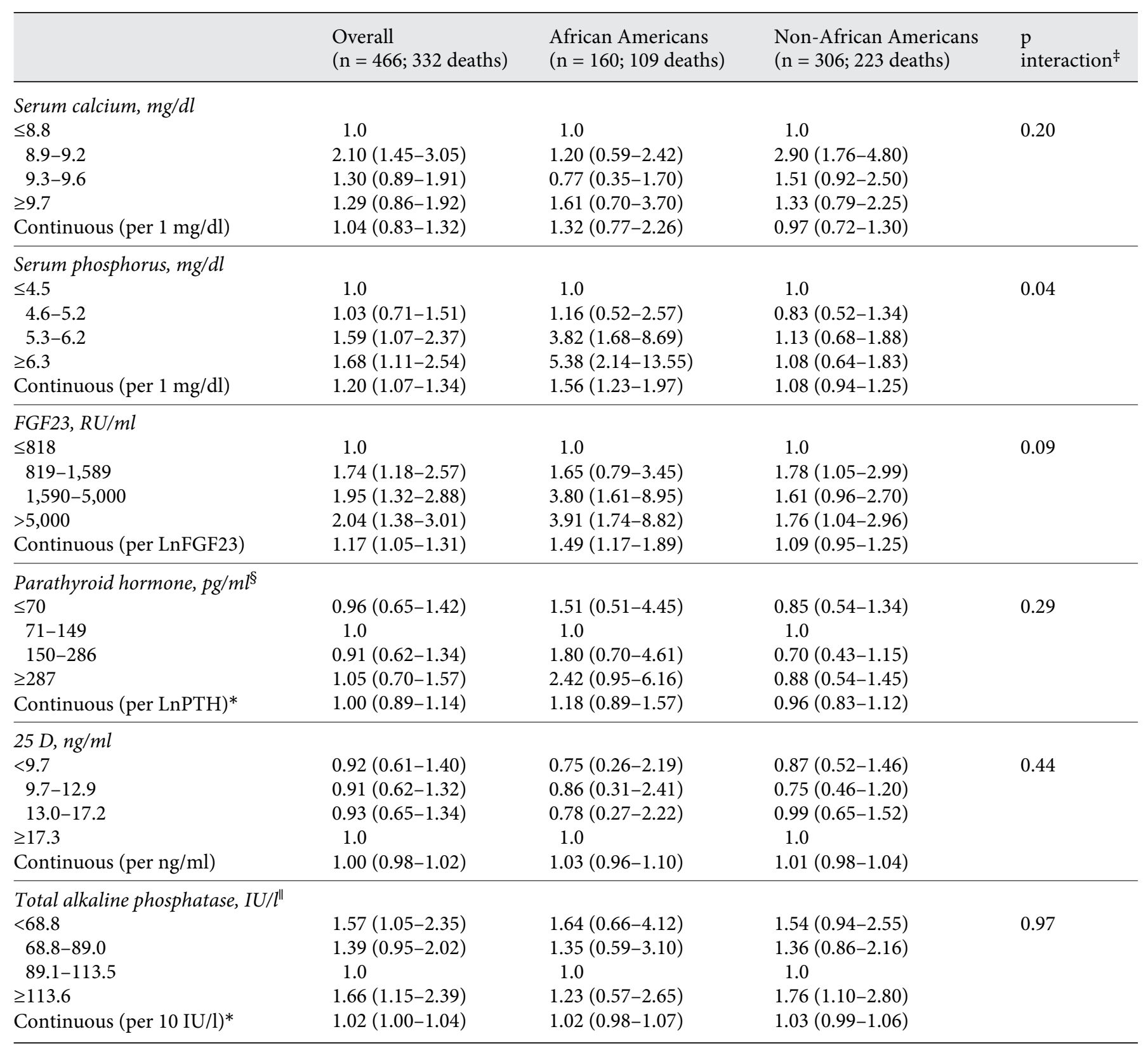

${ }^{\dagger}$ Adjusted for age, sex, race (overall model) education, smoking, BMI, baseline ICED, baseline diabetes mellitus, baseline cardiovascular disease, serum albumin and hemoglobin.

${ }^{\ddagger} \mathrm{p}$ interaction from fully adjusted model in which mineral parameter was modeled as a continuous variable. Due to some evidence of non-linearity in quartile models, continuous parathyroid hormone and total alkaline phosphatase were modeled using restricted cubic splines for interaction testing.

$\S_{n}=409$ with available parathyroid hormone; quartile 2 is used as reference quartile due to possible non-linear relationship with outcomes.

${ }^{\|} \mathrm{n}=466$ with available total alkaline phosphatase. Quartile 3 is used as the reference quartile due to prior reports of non-linear relationships with outcomes.

* Continuous model tests linear relation between PTH or total alkaline phosphatase and outcome. 
Table 3. Adjusted ${ }^{\dagger}$ hazard ratio $(95 \% \mathrm{CI})$ of cardiovascular mortality by selected mineral parameters and stratified by race

$\begin{array}{lll}\begin{array}{l}\text { Overall } \\ (\mathrm{n}=466 ; 146 \text { events })\end{array} & \begin{array}{l}\text { African Americans } \\ (\mathrm{n}=160 ; 39 \text { events })\end{array} & \begin{array}{l}\text { Non-African Americans } \\ (\mathrm{n}=306 ; 107 \text { events })\end{array}\end{array}$

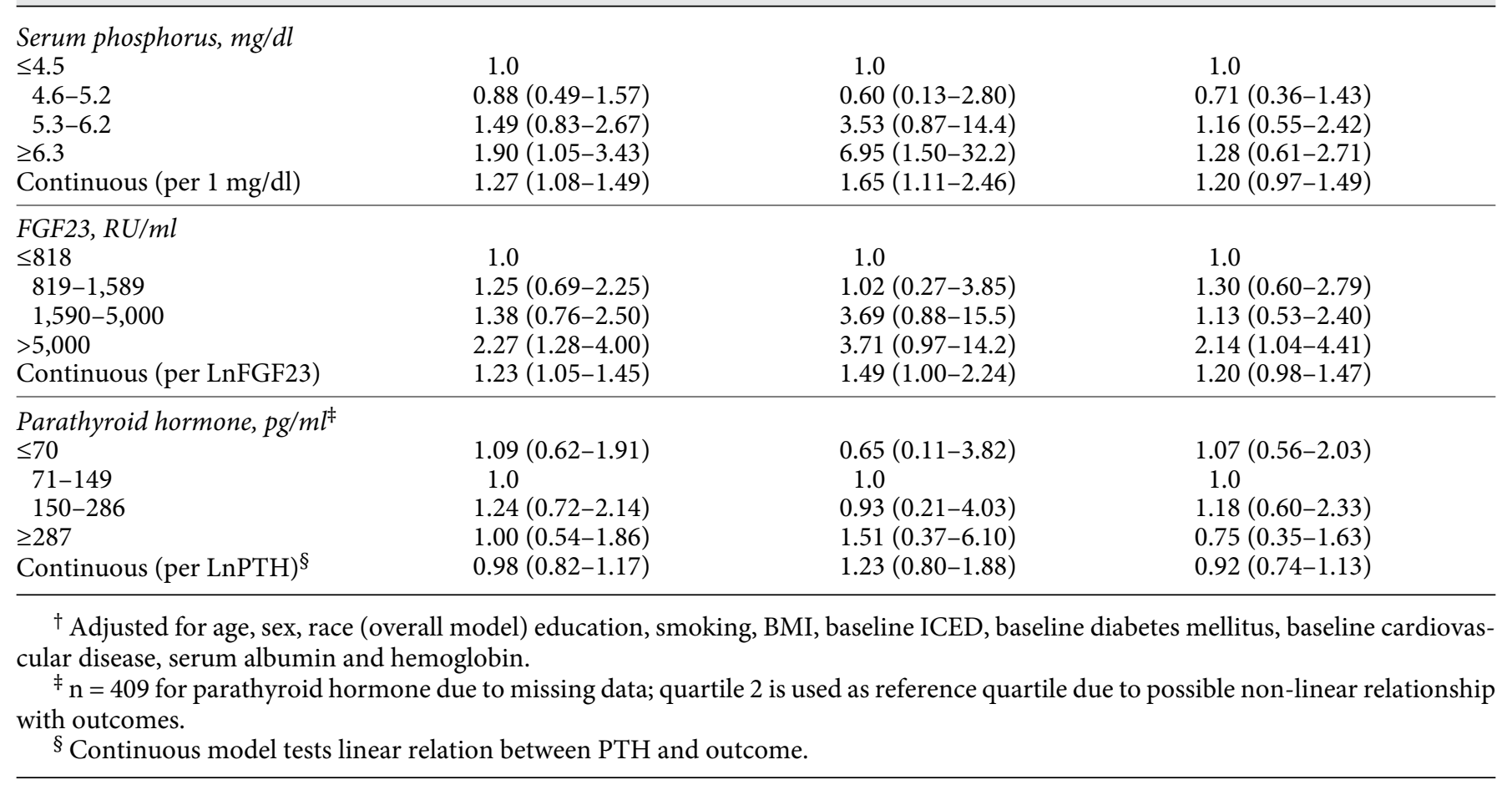

relationship between higher FGF23 was evident among African Americans ( $\mathrm{p}=0.001$; HR 3.91, 95\% CI 1.74-8.82 for the highest vs. lowest quartile). Quartiles 2 and 4 were associated with higher risk compared to quartile 1 in nonAfrican Americans, but there was no relationship between log-transformed FGF23 and mortality in continuous analyses $(\mathrm{p}=0.23$, $\mathrm{p}$-interaction $=0.09)$.

\section{Association of PTH, $25 \mathrm{D}$ and Total Alkaline \\ Phosphatase with Mortality}

PTH and 25 D were not associated with outcomes in any models. The highest and lowest quartiles of total alkaline phosphatase were associated with higher mortality overall, but there was no interaction by race (table 2).

\section{Secondary and Sensitivity Analyses}

Results from models of cardiovascular mortality revealed similar estimates, although power was limited to test interaction (table 3 ). In sensitivity analyses, additional adjustment for inflammatory markers or use of racespecific quartiles in lieu of overall quartiles did not meaningfully modify the results (data not shown). Analyses restricted to participants who missed fewer than $3 \%$ of their hemodialysis sessions (online suppl. fig. 2) and those with $\geq 250 \mathrm{ml} /$ day of urine output were similar to primary analyses (online suppl. fig. 3 ).

\section{Discussion}

We report increased relative risk of all-cause and cardiovascular mortality associated with aberrant phosphorus metabolism, as indicated by higher serum phosphorus and FGF23, in patients recently initiating hemodialysis. The relative risks associated with higher phosphorus were evident only among African Americans, whereas the risks associated with FGF23 were evident in both groups, but greater in African Americans compared to non-African Americans. Both higher and lower levels of total alkaline phosphatase were associated with mortality overall and there was no interaction by race. Prior studies in incident ESRD patients also found greater risk associated with elevated FGF23 in African Americans compared to non-African Americans [1]. Our study extends these findings over a long followup period and includes multiple mineral parameters 
and their association with overall and cardiovascular mortality.

Our results differ from a previous report in a large cohort of prevalent hemodialysis patients [18]. In this study, there was no meaningful modification in the relationship between calcium, phosphorus, PTH and alkaline phosphatase by race. FGF23 was not measured and unlike our study, the majority of participants were using active vitamin D sterols, which may provide a survival benefit despite raising serum phosphorus [19]. In addition, it is possible that the use of prevalent, as opposed to incident dialysis patients that were studied here, may have contributed to the disparate findings $[1,18]$.

The differences in mean levels of mineral parameters by race in this study mirror prior findings with higher levels of PTH among African Americans [20, 21], despite lower FGF23 and phosphorus [18, 22-24]. This constellation of abnormalities could be consistent with more severe 1,25-dihydroxyvitamin D deficiency in African Americans, but we were not able to measure these levels to confirm this. We only had information on the use of intravenous calcitriol and not on the use of other vitamin D analogues that may have been in use during the follow-up period. The overall limited use of calcitriol at baseline in this cohort may have the advantage of revealing associations without confounding by treatment status or dose, but findings could differ in a more contemporary, treated cohort, particularly in light of changing PTH treatment guidelines over this time [25]. Also, we did not have information available on the use of phosphorus binders; however, we do have data on achieved serum phosphorus, which has been commonly associated with outcomes in other cohorts [2].

In this study, $25 \mathrm{D}$ levels, which were low in most of the participants, were not associated with mortality in either African Americans or non-African Americans. Similarly, no relationship between $25 \mathrm{D}$ and death or ESRD events was found in a recent study of African Americans with pre-dialysis CKD [16]. It is important to note that our study was initiated in 1995-1998 when nutritional vitamin D supplementation was not widespread, which may explain universally low levels. Our results confirm findings of another recently reported cohort of patients with advanced CKD and ESRD, in which 1-25-hydroxyvitamin $\mathrm{D}$, but not $25 \mathrm{D}$, was associated with death [23], reflecting risk that could be attributable to impaired 1-a hydroxylation due to FGF23 elevation. This group of results differs from the general population and other studies of CKD and ESRD populations in which low $25 \mathrm{D}$ was associated with higher mortality [26-32]. In the prior studies of incident hemodialysis patients, only severe deficiency was associated with increased mortality [28], or risk was evaluated only for early dialysis mortality, within 90 days, in which low $25 \mathrm{D}$ may have reflected an already declining health status [27].

It is unclear whether the differences in risk associated with aberrant phosphorus metabolism by race represent true heterogeneity in the biological impact of mineral homeostasis in African Americans on dialysis or are the result of differences in other characteristics of African Americans compared to non-African Americans with ESRD. African Americans on dialysis tend to be younger and have fewer comorbid diseases compared to nonAfrican Americans [33], differences that may be attributable to a higher prevalence of major risk alleles for kidney disease $[34,35]$. Despite the higher risk for the occurrence of ESRD [36, 37], African Americans on dialysis have better survival compared with non-African Americans in most age groups $[38,39]$. As a result of major genetic contributions to ESRD in African Americans, it is possible that African Americans with ESRD have more organ-limited disease at dialysis initiation [40]. A lower burden of systemic disease in African Americans and longer survival may result in less competing causes of death that are not attributable to dialysis-specific risk factors. As a result, dialysis-specific risk factors may be more easily detected in African American populations. In fact, our group recently reported heterogeneity of the risk association between biomarkers of vascular calcification and mortality according to diabetic status with greater risk evident only among non-diabetics [41] and more linear association between blood pressure and outcomes in lowrisk groups [42]. Each of these results suggests that targeting dialysis-specific risk factors may be most useful in those with lower overall mortality risk.

Alternatively, it may be that the higher risk of adverse outcomes associated with aberrant phosphorus metabolism in African Americans is not merely due to competing risks, but instead attributable to biological differences. True differences in bone and mineral homeostasis by race are suggested by different rates of osteoporosis, vascular calcification, greater peripheral resistance to the actions of PTH [43-45] and genetic differences in the binding and handling of vitamin $\mathrm{D}[9,22,44,46-49]$. A recent study suggests that APOL1, a major risk allele for ESRD in African Americans, may also promote cardiovascular disease [50], underscoring the possibility that genetic differences between African Americans and non-African Americans could result in differing implications of bone and mineral abnormalities and their possible role in cardiovascular disease pathogenesis.
Scialla/Parekh/Eustace/Astor/Plantinga/ Jaar/Shafi/Coresh/Powe/Melamed 
Our study had several limitations including the fact that it was an observational study where causality cannot be established. Although our data collection in this prospective cohort study was thorough, we may still be missing information on potential confounders that may affect the associations we found including data on control of comorbid illnesses. However, our study also had several strengths. We were able to control for multiple known risk factors, which were collected in a standardized fashion. We had multiple measurements for several mineral metabolism analytes to allow for more comprehensive characterization and physician adjudication of causes of death.

In summary, African Americans have a higher mortality risk with elevated serum phosphate and FGF23 levels compared to non-African Americans. Our findings provide impetus for research examining race-specific treatment targets for bone and mineral parameters and particularly for aberrant phosphorus metabolism. Such studies designed to test interventions of bone and mineral homeostasis should be powered adequately to evaluate possible differences in treatment effects by race.

\section{Acknowledgments}

CHOICE was supported by grants R01DK59616, R01DK080123 from the National Institute of Diabetes and Digestive and Kidney Diseases (NIDDK), Bethesda, Md.; R01HS08365 from the Agency for Health Care Research and Quality, Rockville, Md.; and R01HL62985 from the National Heart Lung and Blood Institute, Bethesda, Md. In addition this work was supported in part by K23DK078774 and U01DK087783 (M.L.M.), K23DK095949 (J.J.S.), K23DK083514 (T.S.) each from the NIDDK; KL2RR025006 (J.J.S.) from the National Center for Research Resources, National Institutes of Health Roadmap for Medical Research; a Carl Gottschalk Award from the American Society of Nephrology (M.L.M.) and a grant from Abbvie Laboratories (R.S.P.). The content is solely the responsibility of the authors and does not necessarily represent the official views of the Agency for Health Care Research and Quality, National Heart Lung and Blood Institute, NIDDK, National Institutes of Health, or Abbvie Laboratories. We thank the patients, staff and medical directors of the participating clinics and the DCI Central Laboratory who contributed to the study.

\section{Disclosure Statement}

R.S. Parekh: research funding from Abbvie Laboratories. All other authors have nothing to disclose.

\section{References}

1 Gutiérrez OM, Mannstadt M, Isakova T, Rauh-Hain JA, Tamez H, Shah A, et al: Fibroblast growth factor 23 and mortality among patients undergoing hemodialysis. N Engl J Med 2008;359:584-592.

2 Block GA, Hulbert-Shearon TE, Levin NW, Port FK: Association of serum phosphorus and calcium $\mathrm{x}$ phosphate product with mortality risk in chronic hemodialysis patients: a national study. Am J Kidney Dis 1998;31: 607-617.

3 Silver J, Naveh-Many T: FGF-23 and secondary hyperparathyroidism in chronic kidney disease. Nat Rev Nephrol 2013;9:641-649.

4 Jono S, McKee MD, Murry CE, Shioi A, Nishizawa Y, Mori K, et al: Phosphate regulation of vascular smooth muscle cell calcification. Circ Res 2000;87:E10-E17.

5 Faul C, Amaral AP, Oskouei B, Hu MC, Sloan A, Isakova T, et al: FGF23 induces left ventricular hypertrophy. J Clin Invest 2011;121: 4393-4408.

6 Amann K, Tornig J, Kugel B, Gross M, Tyralla $\mathrm{K}$, El-Shakmak A, et al: Hyperphosphatemia aggravates cardiac fibrosis and microvascular disease in experimental uremia. Kidney Int 2003;63:1296-1301.

7 Lam D, Kao W, Sozio S, Meoni L, Shafi T, Jaar $\mathrm{B}$, et al: Interdialytic ionized calcium is associated with a pro-arrhythmic phenotype in incident dialysis patients: the predictors of arrhythmic and cardiovascular risk in ESRD
(PACE) study. J Am Soc Nephrol 2011;22: 487A.

8 Pun PH, Horton JR, Middleton JP: Dialysate calcium concentration and the risk of sudden cardiac arrest in hemodialysis patients. Clin J Am Soc Nephrol 2013;8:797-803.

9 Bell NH, Greene A, Epstein S, Oexmann MJ, Shaw S, Shary J: Evidence for alteration of the vitamin D-endocrine system in blacks. J Clin Invest 1985;76:470-473.

10 Kendrick J, Cheung AK, Kaufman JS, Greene T, Roberts WL, Smits G, et al; HOST Investigators: FGF-23 associates with death, cardiovascular events, and initiation of chronic dialysis. J Am Soc Nephrol 2011;22:19131922.

11 Robinson-Cohen C, Hoofnagle AN, Ix JH, Sachs MC, Tracy RP, Siscovick DS, et al: Racial differences in the association of serum 25-hydroxyvitamin D concentration with coronary heart disease events. JAMA 2013; 310:179-188.

12 Melamed ML, Eustace JA, Plantinga L, Jaar BG, Fink NE, Coresh J, et al: Changes in serum calcium, phosphate, and PTH and the risk of death in incident dialysis patients: a longitudinal study. Kidney Int 2006;70:351357.

13 Miskulin DC, Martin AA, Brown R, Fink NE, Coresh J, Powe NR, et al: Predicting 1 year mortality in an outpatient haemodialysis population: a comparison of comorbidity instru- ments. Nephrol Dial Transplant 2004;19: 413-420.

14 Athienites NV, Miskulin DC, Fernandez G Bunnapradist S, Simon G, Landa M, et al: Comorbidity assessment in hemodialysis and peritoneal dialysis using the index of coexistent disease. Semin Dial 2000;13:320-326.

15 Liu Y, Coresh J, Eustace JA, Longenecker JC, Jaar B, Fink NE, et al: Association between cholesterol level and mortality in dialysis patients: role of inflammation and malnutrition. JAMA 2004;291:451-459.

16 Scialla JJ, Astor BC, Isakova T, Xie H, Appel LJ, Wolf M: Mineral metabolites and CKD progression in African Americans. J Am Soc Nephrol 2013;24:125-135.

17 Block GA, Klassen PS, Lazarus JM, Ofsthun N, Lowrie EG, Chertow GM: Mineral metabolism, mortality, and morbidity in maintenance hemodialysis. J Am Soc Nephrol 2004; 15:2208-2218.

18 Kalantar-Zadeh K, Miller JE, Kovesdy CP, Mehrotra R, Lukowsky LR, Streja E, et al: Impact of race on hyperparathyroidism, mineral disarrays, administered vitamin $\mathrm{D}$ mimetic, and survival in hemodialysis patients. J Bone Miner Res 2010;25:2724-2734.

19 Wolf M, Betancourt J, Chang Y, Shah A, Teng $\mathrm{M}$, Tamez H, et al: Impact of activated vitamin $\mathrm{D}$ and race on survival among hemodialysis patients. J Am Soc Nephrol 2008;19:1379_ 1388. 
20 Ennis J, Worcester E, Coe F: Contribution of calcium, phosphorus and 25-hydroxyvitamin D to the excessive severity of secondary hyperparathyroidism in African-Americans with CKD. Nephrol Dial Transplant 2012;27: 2847-2853.

21 Gupta A, Kallenbach LR, Zasuwa G, Divine GW: Race is a major determinant of secondary hyperparathyroidism in uremic patients. J Am Soc Nephrol 2000;11:330-334.

22 De Boer IH, Gorodetskaya I, Young B, Hsu CY, Chertow GM: The severity of secondary hyperparathyroidism in chronic renal insufficiency is GFR-dependent, race-dependent, and associated with cardiovascular disease. J Am Soc Nephrol 2002;13:2762-2769.

23 Kendrick J, Cheung AK, Kaufman JS, Greene T, Roberts WL, Smits G, et al; HOST (Homocysteinemia in Kidney and End Stage Renal Disease) Study Investigators: Associations of plasma 25-hydroxyvitamin D and 1,25-dihydroxyvitamin D concentrations with death and progression to maintenance dialysis in patients with advanced kidney disease. Am J Kidney Dis 2012;60:567-575.

24 Jovanovich A, Chonchol M, Cheung AK, Kaufman JS, Greene T, Roberts WL, et al: Racial differences in markers of mineral metabolism in advanced chronic kidney disease. Clin J Am Soc Nephrol 2012;7:640-647.

25 Kidney Disease: Improving Global Outcomes (KDIGO) CKD-MBD Work Group: KDIGO clinical practice guideline for the diagnosis, evaluation, prevention, and treatment of chronic kidney disease-mineral and bone disorder (CKD-MBD). Kidney Int Suppl 2009; 113:S1-S130.

26 Melamed ML, Michos ED, Post W, Astor B: 25-hydroxyvitamin D levels and the risk of mortality in the general population. Arch Intern Med 2008;168:1629-1637.

27 Wolf M, Shah A, Gutierrez O, Ankers E, Monroy $M$, Tamez $H$, et al: Vitamin D levels and early mortality among incident hemodialysis patients. Kidney Int 2007;72:1004-1013.

28 Drechsler C, Verduijn M, Pilz S, Dekker FW, Krediet RT, Ritz E, et al: Vitamin D status and clinical outcomes in incident dialysis patients: results from the NECOSAD study. Nephrol Dial Transplant 2011;26:1024-1032.

29 Dobnig H, Pilz S, Scharnagl H, Renner W, Seelhorst U, Wellnitz B, et al: Independent as- sociation of low serum 25-hydroxyvitamin D and 1,25-dihydroxyvitamin D levels with allcause and cardiovascular mortality. Arch Intern Med 2008;168:1340-1349.

30 Navaneethan SD, Schold JD, Arrigain S, Jolly SE, Jain A, Schreiber MJ Jr, et al: Low 25-hydroxyvitamin $\mathrm{D}$ levels and mortality in nondialysis-dependent CKD. Am J Kidney Dis 2011;58:536-543.

31 Pilz S, Tomaschitz A, Friedl C, Amrein K, Drechsler C, Ritz E, et al: Vitamin D status and mortality in chronic kidney disease. Nephrol Dial Transplant 2011;26:36033609.

32 Zittermann A, Iodice S, Pilz S, Grant WB, Bagnardi V, Gandini S: Vitamin D deficiency and mortality risk in the general population: a meta-analysis of prospective cohort studies. Am J Clin Nutr 2012;95:91-100.

33 Kucirka LM, Grams ME, Lessler J, Hall EC, James N, Massie AB, et al: Association of race and age with survival among patients undergoing dialysis. JAMA 2011;306:620626.

34 Foster MC, Coresh J, Fornage M, Astor BC, Grams M, Franceschini N, et al: APOL1 variants associate with increased risk of CKD among African Americans. J Am Soc Nephrol 2013;24:1484-1491.

35 Parsa A, Kao WH, Xie D, Astor BC, Li M, Hsu $\mathrm{CY}$, et al: APOL1 risk variants, race, and progression of chronic kidney disease. N Engl J Med 2013;369:2183-2196.

36 Grams ME, Chow EK, Segev DL, Coresh J: Lifetime incidence of CKD stages 3-5 in the United States. Am J Kidney Dis 2013;62:245252.

37 Kiberd BA, Clase CM: Cumulative risk for developing end-stage renal disease in the US population. J Am Soc Nephrol 2002;13:16351644 .

38 Crews DC, Sozio SM, Liu Y, Coresh J, Powe NR: Inflammation and the paradox of racial differences in dialysis survival. J Am Soc Nephrol 2011;22:2279-2286.

39 Yan G, Norris KC, Yu AJ, Ma JZ, Greene T, $\mathrm{Yu} \mathrm{W}$, et al: The relationship of age, race, and ethnicity with survival in dialysis patients. Clin J Am Soc Nephrol 2013;8:953-961.

40 Buckalew VM Jr, Freedman BI: Reappraisal of the impact of race on survival in patients on dialysis. Am J Kidney Dis 2010;55:1102-1110.
41 Scialla J, Kao WH, Crainiceanu C, Sozio SM, Oberai PC, Shafi T, et al: Biomarkers of vascular calcification and mortality in patients with ESRD. Clin J Am Soc Nephrol 2014;9: 745-755.

42 Shafi T, Zager PG, Sozio SM, Grams ME, Jaar BG, Christenson RH, et al: Troponin I and NT-proBNP and the association of systolic blood pressure with outcomes in incident hemodialysis patients: the Choices for Healthy Outcomes in Caring for ESRD (CHOICE) Study. Am J Kidney Dis 2014;64:443-451.

43 Wassel CL, Pankow JS, Peralta CA, Choudhry $S$, Seldin MF, Arnett DK: Genetic ancestry is associated with subclinical cardiovascular disease in African-Americans and Hispanics from the Multi-Ethnic Study of Atherosclerosis. Circ Cardiovasc Genet 2009;2:629-636.

44 Bild DE, Detrano R, Peterson D, Guerci A, Liu $\mathrm{K}$, Shahar E, et al: Ethnic differences in coronary calcification: the Multi-Ethnic Study of Atherosclerosis (MESA). Circulation 2005; 111:1313-1320.

45 Weinstein RS, Bell NH: Diminished rates of bone formation in normal black adults. $\mathrm{N}$ Engl J Med 1988;319:1698-1701.

46 Powe CE, Evans MK, Wenger J, Zonderman $\mathrm{AB}$, Berg AH, Nalls M, et al: Vitamin D-binding protein and vitamin $\mathrm{D}$ status of black Americans and white Americans. N Engl J Med 2013;369:1991-2000.

47 Bhan I, Powe CE, Berg AH, Ankers E, Wenger JB, Karumanchi SA, et al: Bioavailable vitamin D is more tightly linked to mineral metabolism than total vitamin $\mathrm{D}$ in incident hemodialysis patients. Kidney Int 2012;82:8489.

48 Cosman F, Morgan DC, Nieves JW, Shen V, Luckey MM, Dempster DW, et al: Resistance to bone resorbing effects of PTH in black women. J Bone Miner Res 1997;12: 958-966.

49 Levin GP, Robinson-Cohen C, de Boer IH, et al: Genetic variants and associations of 25-hydroxyvitamin D concentrations with major clinical outcomes. JAMA 2012;308:18981905.

50 Ito K, Bick AG, Flannick J, Friedman DJ, Genovese G, Parfenov MG, et al: Increased burden of cardiovascular disease in carriers of APOL1 genetic variants. Circ Res 2014;114: 845-850. 